\title{
Sclerosing cholangitis, race and sex
}

\author{
P Kelly, S Patchett, D McCloskey, E Alstead, M Farthing, P Fairclough
}

\begin{abstract}
Background-Primary sclerosing cholangitis develops in $3-10 \%$ of patients with ulcerative colitis, and may be associated with an increased cancer risk. Ulcerative colitis is probably less common in people of African origin than in populations of European descent.

Aims and methods-To review the records of all patients under regular follow up for ulcerative colitis at St Bartholomew's Hospital (London, UK) , a tertiary referral centre, prompted by discovering a cluster of cases with common features.

Results and conclusions-Among 166 patients with ulcerative colitis under regular follow up, only four (all women) are of African or Caribbean genetic origin, and three of these have developed sclerosing cholangitis within three years of presentation with colitis, compared with four of 162 patients of European or Asian descent (odds ratio 119, 95\% confidence interval $8-3837 ; p=0.0002)$. This cluster, which is not explained by common HLA DR or DQ type, suggests that Africans and AfroCaribbeans, especially women, may be at increased risk of sclerosing cholangitis. This may reflect genetic influences on the development of enteric and hepatobiliary inflammatory disease.

(Gut 1997; 41: 688-689)
\end{abstract}

Keywords: sclerosing cholangitis; ulcerative colitis; genetics of inflammatory bowel disease; racial effects on disease

Digestive Diseases

Research Centre,

St Bartholomew's and

the Royal London

School of Medicine

and Dentistry,

2 Newark Street,

London E1 2AT, UK

P Kelly

S Patchett

E Alstead

M Farthing

P Fairclough

Tissue typing

laboratory, The Royal

London Hospital,

London E1, UK

D McCloskey

Correspondence to:

Dr Paul Kelly.

Accepted for publication 24 June 1997 ulcerative colitis. ${ }^{6}$ However, our recent experience suggests that this association may be stronger in a subgroup defined by race and sex.
Methods and Results

We have reviewed the records of all patients under regular follow up for ulcerative colitis in this institution, a tertiary referral centre, prompted by discovering a cluster of cases with common features. Since 1991, we have diagnosed PSC in three young black women. The first, aged 31 years, was born in the United Kingdom of black Caribbean parents and presented with a five year history of intermittent diarrhoea. An increased serum alkaline phosphatase concentration was noted at the time the diagnosis of ulcerative colitis was made by sigmoidoscopic biopsy. As itching began to dominate the clinical picture, PSC was diagnosed by endoscopic retrograde cholangiopancreatography (ERCP). Orthotopic liver transplantation was required three years after the initial presentation with ulcerative colitis, because of intractable itching. She is HLA DR $7,15,51,53$, DQ 1,2 , and serum is positive for antinuclear and cytoplasmic type (c-type) antineutrophil cytoplasmic antibodies (ANCA). The second patient, aged 18 at presentation, is of West African origin and birth, and a homozygote for the $S$ haemoglobin gene, although with minimal symptoms of sickle disease. She was diagnosed as having ulcerative colitis in 1988 at the age of 12 years, found to have a notably raised alkaline phosphatase concentration in 1991, and diagnosed with PSC in 1996, with few symptoms attributable to the biliary dysfunction. She is HLA DR 0102(1), 0301(17), 52, DQ 2, 5, and serum is positive for antinuclear and c-type ANCA. The third patient, West African born and bred, was 32 years old at presentation with ulcerative colitis. Within two months her serum alkaline phosphatase concentration was notably raised. Further investigations were interrupted by semi-urgent colectomy, but in due course ERCP revealed severe changes of PSC with narrowed and beaded intrahepatic bile ducts. She is HLA DR 15,51 , DQ 6, but her autoantibody status is unknown. In all three patients the diagnosis of PSC was made within three years of presentation of ulcerative colitis, and has run an aggressive course in two. In all three cases the ulcerative colitis extended throughout the colon. This cluster of cases is not explained by shared HLA DR genotype.

Of a total of 166 patients with ulcerative colitis currently under regular follow up at St Bartholomew's Hospital, only four are of African or Caribbean origin, and of these three (described earlier) have recently developed PSC. The other black woman still free of the disease has HLA DR type 1, 15, 51 DQ 5, 6, and is negative for ANCA. Four (three women, one man) of 162 patients of other racial origin 
TABLE 1 PSC complicating ulcerative colitis according to racial classification

\begin{tabular}{llc}
\hline Origin & PSC present & PSC absent \\
\hline African/Caribbean & 3 & 1 \\
White/Indian & 4 & 158 \\
\hline
\end{tabular}

Odds ratio $119 ; 95 \%$ confidence interval $8-3837 ; \mathrm{p}=0.0002$ by Fisher's exact test.

(all white European) have also been diagnosed as having PSC (table 1).

\section{Discussion}

The cluster we describe may indicate an association which would be of interest in understanding genetic contributions to inflammatory bowel and hepatobiliary disease. Although based on few cases, the association in this institution between race and PSC is striking, and suggests that women of African genetic origin with ulcerative colitis are more likely to develop PSC. All of these women developed attributable symptoms while living in the United Kingdom. To our knowledge, only one previous report has specifically described PSC in people of African genetic origin. ${ }^{5}$ In that study, PSC developed in $12 \%$ of black North American patients. The association in that study was not as strong as in the patients reported here. This might be at least partly explained if there has been greater racial mixing in American blacks than in the patients of African genetic origin seen in London. PSC has been associated with the HLA DR phenotypes B8, DR2, DR3, DR4, and Drw52a, ${ }^{7}$ but there was no consistency in the HLA DR phenotype or genotype of our patients. None of these patients had HLA DR4, previously associated with rapid progression of the cholangitis. ${ }^{8}$ Two of them had c-type ANCA antibodies, rather than the perinuclear ANCA antibodies usually associated with PSC. ${ }^{9}$

It has recently been suggested that patients with PSC and ulcerative colitis have an increased risk of colorectal cancer compared with patients with ulcerative colitis but without PSC, ${ }^{10}$ further emphasising the importance of the interaction of these inflammatory disorders. Although any association of race, sex and PSC in colitic patients could be due to exposure to an environmental factor or to an unrecognised selection bias, these three patients differ in their upbringing and there is a distinct possibility that any association is genetic.

We thank Wendy Draper for her work on the database.

1 Segal I. Ulcerative colitis in a developing country of Africa: the Baragwanath experience of the first 46 patients. Int $\mathcal{F}$ Colorect Dis 1988; 3: 222-5.

2 O'Donoghue DP, Clark ML. Inflammatory bowel disease in West Indians. BMF 1976; ii: 796.

3 Benfield G, Asquith P. Ulcerative colitis in West Indian immigrants. $Q \mathcal{F} \mathrm{Med} 1986$; 229: 489-95.

4 Garland CF, Lilienfeld AM, Mendeloff AI, Markowitz JA, Terrell KB, Garland FC. Incidence rates of ulcerative colitis and Crohn's disease in fifteen areas of the United States. tis and Crohn's disease in fifteen areas
Gastroenterology 1981; 81: 1115-24.

5 Simsek H, Schuman BM. Inflammatory bowel disease in 64 black patients: analysis of course, complications and surgery. F Clin Gastroenterol 1989; 11: 294-8.

6 Chapman RW. Aetiology and natural history of primary sclerosing cholangitis - a decade of progress? Gut 1991; 32: 1433-5.

7 Lee YM, Kaplan M. Primary sclerosing cholangitis. N Engl f Med 1995; 332: 924-33.

8 Mehal WZ, Lo YM, Wordsworth BP, Neuberger JM, Hubscher SC, Flemming KA, et al. HLA-DR4 is a marker for rapid disease progression in PSC. Gastroenterology 1994; 106: $160-7$

9 Snook JA, Chapman RW, Fleming K, Jewell DP. Antineutrophil nuclear antibody in ulcerative colitis, Crohn's disease, and primary sclerosing cholangitis. Clin Exp Immunol 1989; 76: 30-3.

10 Brentnall TA, Haggitt RC, Rabinovitch PS, Kimmey MB, Bronner MP, Levine DS, et al. Risk and natural history of colonic neoplasia in patients with primary sclerosing cholangitis and ulcerative colitis. Gastroenterology 1996; 110: $331-8$. 